\title{
Testing for cattle allergy: modified diagnostic cutoff levels improve sensitivity in symptomatic claw trimmers
}

\author{
Astrid Heutelbeck • Natalja Dik · Ernst Hallier • \\ Torsten Zuberbier $\cdot$ Karl-Christian Bergmann
}

Received: 17 January 2010/ Accepted: 28 June 2010/Published online: 24 July 2010

(c) The Author(s) 2010. This article is published with open access at Springerlink.com

\begin{abstract}
Background The diagnosis of cattle-related sensitization is complicated by the variability and complexity of cattle allergen extracts.

Objective To evaluate a modified diagnostic procedure leading to more accurate results especially in the early phase of sensitization.

Methods We tested 27 claw trimmers with and 65 without cattle-related symptoms using two commercially available cattle allergen extracts. We also used a self-prepared cattle allergen mix designed to represent the full spectrum of cattle allergens from a typical agricultural workplace.

Results More than $50 \%$ of symptomatic claw trimmers showed negative test results with commercial extracts and a sensitization cutoff point of $0.35 \mathrm{kU} / \mathrm{l}$. In contrast, with the self-prepared cattle allergen mix, positive results were observed for almost all of them. Evaluating the results of the commercial test kits at different cutoff levels, we found an ideal cutoff point to improve the sensitivity at $0.2 \mathrm{kU} / \mathrm{l}$. Conclusion Additional tests with self-made cattle hair extracts can help to bridge the diagnostic gap seen in patients showing cattle-related symptoms, but negative results in commercially available tests. For early-stage sensitization screening, we propose to lower the cutoff level indicating sensitization to $0.2 \mathrm{kU} / \mathrm{l}$.
\end{abstract}

\footnotetext{
A. Heutelbeck $(\square) \cdot$ N. Dik · E. Hallier

Institute for Occupational and Social Medicine,

University of Göttingen, Waldweg 37,

37037 Göttingen, Germany

e-mail: aheutel@gwdg.de

T. Zuberbier · K.-C. Bergmann

Department of Dermatology and Allergy, Charité Berlin,

Charité-Platz 1, 10117 Berlin, Germany
}

Keywords Occupational allergy · Cattle allergy · Cattle allergens - Diagnostic testing - Immunoblotting . Sensitivity

\section{Introduction}

Farming ranks among the occupations with the highest allergy risk; especially, asthma caused by cattle allergens is a significant occupational health problem in many countries (Greskevitch et al. 2007; Heutelbeck et al. 2007; Linaker and Smedley 2002; Reijula and Patterson 1994). Occupational asthma caused by cattle allergens can have significant economic and occupational consequences for the affected workers, especially as many of the patients are young at the time of diagnosis (Heutelbeck et al. 2007). Early diagnosis may help to avoid the manifestation of an overt allergic disease, as it allows the implementation of effective prevention strategies.

Cattle allergen test kits from different manufacturers are available for routine use. However, results of in vivo and in vitro tests are often inconsistent even in cases with undisputedly cattle-related symptoms. Clinical experience confirms the previously published observation that tests with commercially available cattle allergen extracts occasionally show only slightly positive or even negative results, though the tested patients clearly exhibit cattle-related symptoms (Wortmann 1984; Fuchs et al. 1981). Positive reactions to tests with the hair of the patients' own cattle have been reported in the absence of a correspondingly positive result with commercial test kits (Heutelbeck et al. 2007). In a number of cases, allergy tests with extracts from the hair of the patients' cattle or cattle of the same breed has yielded better results; similar phenomena have been described elsewhere (Prahl et al. 1978; Ylönen et al. 
1990). Discordance between negative results using commercial test kits and undisputedly cattle-related symptoms seems to be related to the composition of the commercially available cattle allergen extracts and the diagnostic procedures (Heutelbeck et al. 2009).

The aim of this study was to improve the accuracy of commercial test kits for cattle-related sensitization by evaluating the sensitivity of the commercially available allergen extracts on the basis of anamnestic data. Claw trimmers are the most suitable occupation for the study of cattle allergy since they have a close contact to these animals during almost the entire shift and do not perform tasks with exposure to other sources of allergens such as fodder or grain. Thus, constant high cattle allergen exposure was expected. We compared the results of two different commercial cattle allergen tests with the anamnestic data concerning the existence or not of cattle-related symptoms. Assuming the work-related symptomatic to be cattle-related, we also tested a self-prepared cattle allergen mix designed to represent the full spectrum of cattle allergens from a typical agricultural workplace of claw trimmers with work-related symptoms.

\section{Materials and methods}

We invited all claw trimmers who were members of the three biggest unions in Germany to take part in this study. We contacted them at professional education courses organized by the claw trimmer unions in the Experimental Station for Animal Husbandry in Lower Saxony, Echem, Germany, the Experimental Station for Animal Husbandry in the Free State of Bavaria, Achselschwang, Germany and the Experimental Station of the Saxon State Department of the Environment, Agriculture and Geology, Lohmen, Germany.

A free medical consultation to assess the personal risk of developing cattle allergy was offered to all claw trimmers. This consultation consisted of recording the relevant medical history and performing serological allergy tests.

\section{Medical history}

We recorded general and work-associated allergy symptoms relating to the upper airways (such as itchy and stuffy nose or sneezing), lower airways (shortness of breath, asthma, coughing), eyes (conjunctivitis, red, itching and watery eyes) and skin (itching, eczema). Furthermore, information on the working and living environments was collected.

\section{Commercial allergy tests}

Serum samples of the participants were investigated using commercially available enzyme allergosorbent tests (Hycor
Biomedical GmbH, Germany) to determine the concentrations of specific serum IgE antibodies (kU/l) against a panel of ubiquitous inhaled allergens (cat, dog, birch, timothy, Dermatophagoides pteronyssinus and Cladosporium); the results were expressed as negative or positive (defined as $\mathrm{IgE}$ antibody levels $\geq 0.35 \mathrm{kU} / \mathrm{l}$ ). Furthermore, the levels of specific serum IgE antibodies (EAST) against cattle allergen were determined using two different commercially available tests (Hycor Biomedical $\mathrm{GmbH}$, Germany and Phadia, Freiburg, Germany). The results were expressed as IgE antibody level (kU/l), not excluding the range $<0.35 \mathrm{kU} / \mathrm{l}$.

\section{Self-prepared cattle allergen mix}

To detect misclassification or misidentification of sensitized individuals, we additionally applied extracts from the hair of different cattle races found in typical working environments. These additional tests were performed in individuals who either had work-related symptoms or had at least one positive reaction in one or both of the commercial cattle allergen tests.

The hair of purebred adult cattle was obtained from different breeders throughout Germany. Cattle selected for this study were all healthy to avoid a possible influence of pathology on the Bos d 2 production. The hair was cut close to the skin without visible contamination. The hair of these cattle breeds was used because they were most relevant to allergies: German Brown, Holstein-Friesian, Charolais, Jersey/White-blue Belgian, German Red Pied, Blonde Aquitaine, and German Simmental (Heutelbeck et al. 2009).

About $0.3 \mathrm{~g}$ of hair of each individual cow was incubated for different time periods ( $2 \mathrm{~h}$ up to $48 \mathrm{~h}$ ) at $6^{\circ} \mathrm{C}$ in $2 \mathrm{ml}$ of a $0.1 \mathrm{M}$ ammonium hydrocarbonate $\left(\mathrm{NH}_{4} \mathrm{HCO}_{3}\right)$ solution. An incubation period of $24 \mathrm{~h}$ was found to yield optimal results in protein content and SDS-PAGE separation. The extracts were lyophilized and reconstituted in $\mathrm{NH}_{4} \mathrm{HCO}_{3}$. We verified that the lyophilized extracts did not show any differences in total protein content or SDS-PAGE separation compared to the unlyophilized extracts (data not shown). Protein content was determined using the bicinchonic acid procedure (Pierce Chemicals, Rockford, USA). The results were verified using several dilutions of each sample.

Proteins were separated using SDS-PAGE. A 14\% separating gel ("SERVA-Gel TM TG 14-Vertical TrisGlycine Gel”, SERVA, Heidelberg, Germany) was used for performing Coomassie staining of the separated cattle allergen mix, and 15\% separating gel (self-prepared) for the immunoblot experiments. Molecular weights (MW) were estimated by comparison with commercial MW standard mixtures ("SERVA Prestained SDS-PAGE 
Protein Marker 6.5-200 kDa, Liquid Mix” (Immunoblot), "SERVA Unstained SDS-PAGE Protein Marker 6.5-200 kDa, Liquid Mix" (Coomassie) SERVA, Heidelberg, Germany).

Equal amounts of proteins concentrated at $2 \mathrm{mg} / \mathrm{ml}$ for immunoblotting were applied to the polyacrylamide gel electrophoresis, which was conducted at a constant voltage $(150 \mathrm{~V})$ for $90-100 \mathrm{~min}$. The marker protein preparations were run alongside the extract. For the investigation of the protein patterns, the gels were stained with Coomassie blue. The molecular weights of the corresponding allergens were estimated relative to the standard marker proteins. Each extract was investigated in an independent immunoblot experiment.

\section{Detection of allergens (immunoblotting)}

The detection of the allergenic proteins in the extracts was performed by immunoblotting. After separation by SDSPAGE on a $14 \%$ gel ("SERVA-Gel TM TG 14-Vertical Tris-Glycine Gel", SERVA, Heidelberg, Germany), proteins were transferred onto polyvinylidine difluoride (PVDF) membranes in a semi-dry blot apparatus. Membranes were incubated overnight in Roti Block solution (Roth, Karlsruhe, Germany) to block non-specific binding sites, washed with tris-buffered saline (TBS) containing $0.1 \%$ Tween and finally incubated with two serum dilutions (1:5 and 1:10) for $1 \mathrm{~h}$ at room temperature. After washing five times with TBS containing $0.1 \%$ Tween, anti-human IgE monoclonal antibodies diluted to 1:1000, coupled with alkaline phosphatase ("Classical Specific/Total IgE Conjugate" HYCOR Europe, Amsterdam, Netherlands) were added for $1 \mathrm{~h}$ at room temperature. After washing five times with TBS containing $0.1 \%$ Tween, the detection of alkaline phosphatase was performed using the NBT ( $p$-nitro blue tetrazolium chloride)/BCIP (5-bromo-4chloro-3-indoyl phosphate $p$-toluidine salt) system (BioRad, Munich, Germany) according to the recommendations of the manufacturer. We performed immunoblot experiments using sera of non-symptomatic, non-atopic and nonexposed persons $(n=2)$ as well as of non-symptomatic, exposed claw trimmers $(n=3)$ as negative controls to distinguish unspecific reactivity. An immunoblot was defined as positive when specific bands, which were not present in the controls, appeared.

Ethical considerations and data protection

Each participating claw trimmer received a detailed information sheet; consent was given in writing. Personal data were anonymized. The Ethics Committee of the Medical Faculty of the University of Göttingen approved this study (No. 7/9/00).
Statistical analysis

Specific IgE concentrations as determined with commercially available cattle allergen extracts (Hycor or Phadia) were compared at different cutoff levels $(0.35,0.30,0.25$, $0.20,0.15,0.10 \mathrm{kU} / \mathrm{l})$ with the results of the symptomatology (present or not). Specificity, sensitivity and diagnostic efficiency were calculated. "True positive" claw trimmers were characterized to be symptomatic and cattle sensitized (given as specific IgE against cattle detected by commercial tests) and the "true negative" claw trimmers to be nonsymptomatic and non-sensitized (no specific IgE against cattle detected by commercial tests). Statistical comparison between cattle-sensitized and non-sensitized claw trimmers was performed with the Chi-square test to compare data concerning symptomatic versus non-symptomatic, sensitized versus non-sensitized and cattle-sensitized symptomatic versus cattle-sensitized non-symptomatic claw trimmers. A $p$ value of $<0.05$ was considered significant.

\section{Results}

Characteristics of the cohort

A total of 92 claw trimmers (91 male, 1 female) aged between 20 and 59 years (mean 39 years) took part in the free medical test. The participants had been working as claw trimmers for 1-32 years (mean 9 years). All participants had regular contact with cattle of different breeds; 41 of them $(44.6 \%)$ worked as part-time dairy farmers. Some claw trimmers kept pets such as dogs $(n=58 ; 63.0 \%)$ and cats $(n=48 ; 52.2 \%)$.

\section{Allergy symptoms}

A total of 26 claw trimmers (28.3\%) reported general allergy symptoms such as conjunctivitis $(n=8 ; 30.8 \%)$, and symptoms related to the upper airways $(n=7 ; 26.9 \%)$, lower airways $(n=7 ; 26.9 \%)$ and skin $(n=15 ; 57.7 \%)$. As much as $27(29.3 \%)$ claw trimmers reported, sometimes in addition to general symptoms, work-related symptoms such as conjunctivitis $(n=8 ; 29.6 \%)$, upper airway $(n=12 ; 44.4 \%)$, lower airway $(n=9 ; 33.3 \%)$ and skin symptoms $(n=17 ; 63.0 \%)$. Claw trimmers with general allergy symptoms reported workrelated symptoms significantly more frequently (13 of 26 , $50.0 \%)$ than those without $(14$ of $66,21.2 \%)(p<0.05$; relative risk 2.4 ; $95 \%$ confidence interval $1.3-4.3)$.

Sensitization patterns with ubiquitous allergens

In the blood samples taken from 35 of all claw trimmers (38.0\%), specific IgE antibodies against at least one of the 
ubiquitous allergens could be detected. Sensitizations against dust mites $(n=13 ; 14.1 \%), \operatorname{dog}(n=19 ; 20.7 \%)$, cat $(n=14 ; 15.2 \%)$, pollen $(n=17 ; 18.5 \%)$, timothy grass $(n=15 ; 16.3 \%)$, rye $(n=15 ; 16.3 \%)$, mugwort $(n=9 ; 9.8 \%)$, birch $(n=14 ; 15.2 \%)$ and Cladosporium herbarum $(n=1 ; 1.1 \%)$ were found; $45.7 \%(n=16)$ of the 35 ubiquitously sensitized claw trimmers and $17.5 \%$ ( $n=10$ ) of the 57 non-sensitized claw trimmers reported general allergy symptoms of the airways or the skin $(p<0.05)$. The sera of the non-symptomatic persons (nonexposed individuals and claw trimmers) without specific IgE antibodies against the ubiquitous allergens were used as negative controls.

Sensitizations against cattle allergens

In allergological diagnosis using the Hycor test, $19.6 \%$ of all claw trimmers $(n=18)$ showed specific IgE antibodies greater than $0.35 \mathrm{kU} / \mathrm{l}$ against cattle. Of all claw trimmers, $20.7 \%$ ( $n=19$ ) showed negative results in the Hycor test, but reported work-related symptoms. Using the Phadia test, $7 \%$ of all claw trimmers $(n=6)$ showed positive results. Of all claw trimmers, $25.6 \%(n=20)$ showed negative results in the Phadia test, although they reported workrelated symptoms. Combining the results yielded by the two commercial test kits, a sensitization against cattle could be diagnosed with at least one of the commercially available extracts for $21.7 \%$ of all claw trimmers $(n=20)$. Of the 27 claw trimmers with work-related symptoms, $11.1 \%(n=3)$ showed positive results with both, $37.0 \%$ $(n=10)$ in at least one of the commercial tests, and yet $63.0 \%$ ( $n=17$ ) had, in contradiction to their symptoms, negative results with both commercial test kits.

Of the 65 non-symptomatic claw trimmers, $15.4 \%$ ( $n=10$ ) showed a sensitization with the Hycor test, but only $1.5 \%(n=1)$ with the Phadia test. Apart from cattlerelated sensitization, $85.0 \%$ of the 20 claw trimmers with a positive result with the commercial test kits $(n=17)$ were sensitized against at least one ubiquitous allergen; sensitizations against $\operatorname{dog}(n=13)$ and cat $(n=11)$ were significantly more frequent in this group than in the group of claw trimmers without cattle sensitization $(p<0.05)$. The sera of all non-symptomatic individuals (non-exposed individuals and claw trimmers) that were used as negative controls showed no specific IgE antibodies against cattle allergen with the Hycor test or the Phadia test.

Detection of cattle-related sensitizations using immunoblotting

This is the first study presenting the results of a self-prepared cattle allergen mix that was designed to represent the full spectrum of cattle allergens present in a typical agricultural workplace. The self-prepared cattle allergen mix encompasses the spectrum of proteins in a molecular range from lower than $6.5 \mathrm{kDa}$ up to $66 \mathrm{kDa}$ and greater (at approximately 11, 20, 22, 25, 55, 62 and $66 \mathrm{kDa}$ as well as between 25 to 30 and lower than $6.5 \mathrm{kDa}$ ), that was obtained by SDS-PAGE-separation of extracts from the hair of various cattle races (Fig. 1). The allergenic potential of the extracts concerning the different bands was verified using the sera of various confirmed cattle-allergic patients as previously described (Heutelbeck et al. 2009).

In this study, immunoblot investigations with a selfprepared cattle allergen mix were performed on 37 claw trimmers of whom 27 reported work-related symptoms and 20 showed a cattle sensitization with at least one commercial test. Positive specific reactions were detected in $94.6 \%$ of the samples $(n=35)$. Typical results with special attention to different sensitization status, given in the amount of specific IgE $(\mathrm{kU} / \mathrm{l})$ antibodies against cattle with the commercial cattle allergen tests of Hycor and Phadia, are shown in Fig. 2a-d. In most of our immunoblot experiments, we observed distinct bands at a molecular weight of about $16 \mathrm{kDa}$ and rarely in the range of about $20 \mathrm{kDa}$, reflecting the major component bos $\mathrm{d} 2$. Sporadically, specific reactions were seen at a molecular weight of about $6 \mathrm{kDa}$, about $29 \mathrm{kDa}$ and in the range between 14.3 and $21 \mathrm{kDa}$, between 21 and $29 \mathrm{kDa}$, as well as in the range greater than $45 \mathrm{kDa}$, The negative controls of all sera of non-symptomatic non-exposed individuals and nonsensitized, non-symptomatic claw trimmers showed

Fig. 1 SDS-PAGE of the selfprepared cattle allergen mix: prepared extracts were separated using SDS-PAGE. The following marker and samples were applied: lane 1 molecular weight marker (molecular weights given in $\mathrm{kDa}$ ), lane 2 self-prepared cattle allergen mix 

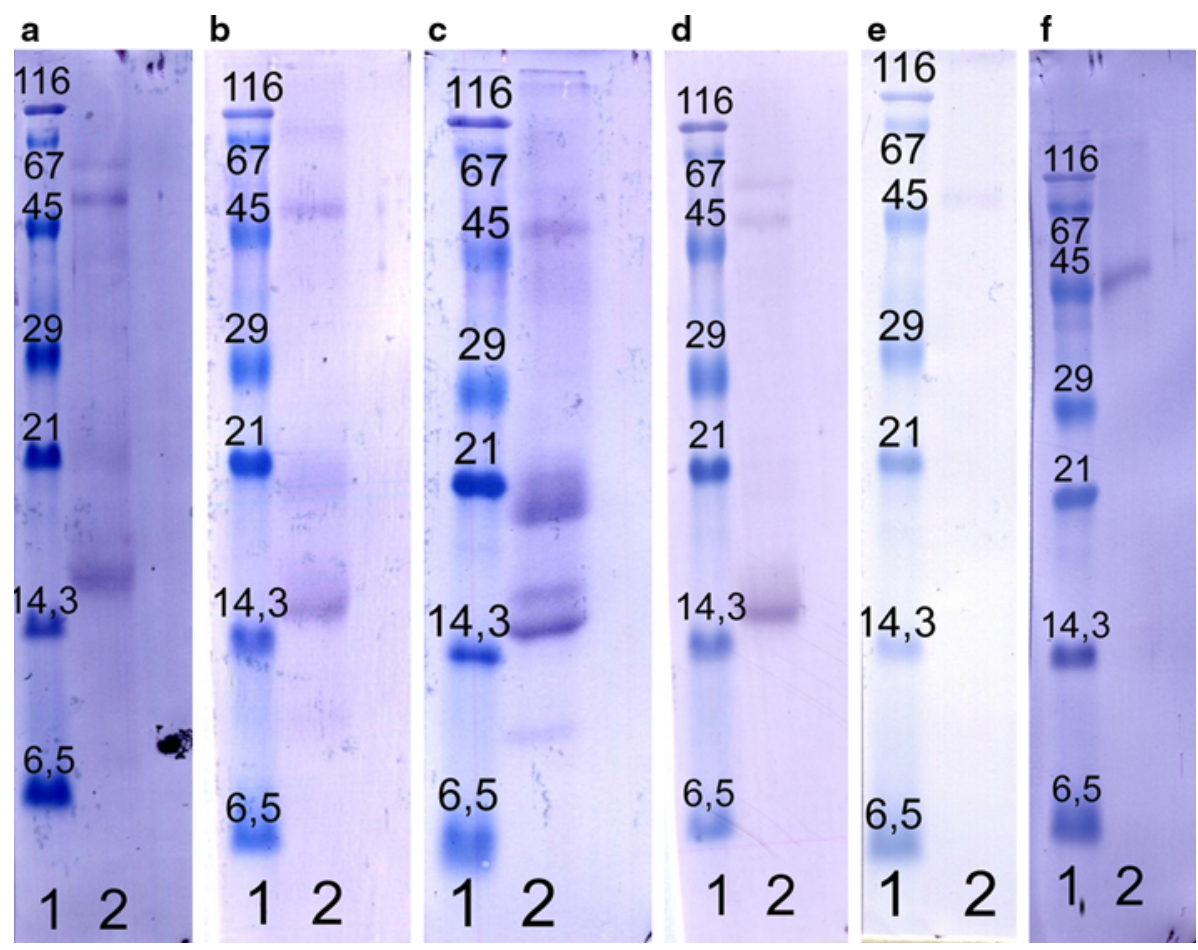

Fig. 2 Immunoblot of the self-prepared cattle allergen mix: proteins were separated by SDS-PAGE and transferred to PVDF membranes. These were developed with serum of symptomatic claw trimmers with different sensitization status, given in the amount of specific IgE $(\mathrm{kU} / \mathrm{l})$ against cattle allergen using the commercial tests of Hycor and Phadia (a-d); a $0.11 \mathrm{kU} / \mathrm{l}$ (Hycor) and $0.05 \mathrm{kU} / \mathrm{l}$ (Phadia), b $0.22 \mathrm{kU} / \mathrm{l}$ (Hycor) and $0.47 \mathrm{kU} / \mathrm{l}$ (Phadia), c $0.45 \mathrm{kU} / \mathrm{l}$ (Hycor) and $0.21 \mathrm{kU} / \mathrm{l}$
(Phadia), d $0.17 \mathrm{kU} / \mathrm{l}$ (Hycor) and $0.00 \mathrm{kU} / \mathrm{l}$ (Phadia). As controls, we used the sera of a non-exposed, non-sensitized individual (e) and a non-sensitized, non-symptomatic claw trimmer (f). The following marker and samples were applied: lane 1 molecular weight marker (molecular weights given in $\mathrm{kDa}$ ), lane 2 self-prepared cattle allergen mix developed with the individual serum unspecific staining in the molecular range between 45 and $67 \mathrm{kDa}$ (examples are shown in Fig. 2e, f).

The immunoblot experiments with the self-prepared cattle allergen mix confirm the positive results obtained with commercial tests in all cases. However, immunoblotting also yielded positive reactions in the sera of participants who had been tested negative with the commercial cattle allergen tests, including 17 participants with negative results in the Hycor test and 29 participants with negative results in the Phadia test. Of the 17 symptomatic claw trimmers with negative results using both commercial cattle allergen tests, 15 showed specific reactions in immunoblotting with the self-prepared cattle allergen mix. Thus, a cattle related sensitization was confirmed by immunoblotting with the self-prepared cattle allergen mix in $92.6 \%(n=25)$ of the symptomatic claw trimmers. The results are shown in Table 1.

Figure 3 presents data obtained for symptomatic claw trimmers (true positive)on sensitivity, specificity and diagnostic efficacy for selected cutoff points of specific IgE antibodies against cattle allergen (in kU/l) for both commercial test kits. The sensitivity of both commercial tests was best at a cutoff level of $0.1 \mathrm{kU} / \mathrm{l}$ and was nearly $70 \%$
(Hycor) and 40\% (Phadia). Specificity at this cutoff point, however, was rather poor especially using the Hycor test (approximately 40\%). The diagnostic efficiency was constantly high at cutoff points of $0.2 \mathrm{kU} / \mathrm{l}$ (Hycor) up to $0.1 \mathrm{kU} / 1$ (Phadia) accompanied by an optimized sensitivity. Altogether, a cutoff point of at least $0.2 \mathrm{kU} / \mathrm{l}$ represented the most advantageous combination of specificity and sensitivity and yielded constantly high diagnostic efficiency for both commercial test kits.

\section{Discussion}

This paper is the first to report the results obtained with a self-prepared cattle allergen mix designed to represent the full spectrum of cattle allergens present in a typical agricultural workplace, as previously characterized with immunoblotting (Heutelbeck et al. 2009). Additional tests with self-made cattle hair extracts can help to bridge the diagnostic gap seen in patients showing cattle-related symptoms, but negative results in tests with commercially available extracts (Heutelbeck et al. 2007, 2009; Prahl et al. 1978; Ylönen et al. 1990). However, the complexity and 
Table 1 Results of serological allergy tests against cattle allergens (given in IU/ml) with the Hycor and Phadia test kits as well as the results (given as positive or negative) shown by immunoblotting with the selfprepared cattle allergen mix in the sera of 27 symptomatic claw trimmers with work-related symptoms

\begin{tabular}{|c|c|c|c|c|c|}
\hline \multirow[t]{2}{*}{ Age, sex } & \multirow{2}{*}{$\begin{array}{l}\text { Known } \\
\text { allergy }\end{array}$} & \multirow{2}{*}{$\begin{array}{l}\text { Work-related } \\
\text { symptoms }\end{array}$} & \multicolumn{3}{|c|}{ Specific IgE against cattle allergens } \\
\hline & & & Hycor $(\mathrm{kU} / \mathrm{l})$ & Phadia $(\mathrm{kU} / \mathrm{l})$ & Immunoblotting \\
\hline 24 years, male & $\checkmark$ & $\checkmark$ & $>100$ & $>100$ & $\boldsymbol{v}$ \\
\hline 27 years, male & $\checkmark$ & $\checkmark$ & 0.19 & 0.10 & $\checkmark$ \\
\hline 32 years, female & & $\checkmark$ & 0.27 & 0.11 & $\boldsymbol{v}$ \\
\hline 33 years, male & & $\boldsymbol{v}$ & 0.01 & 0.01 & Negative \\
\hline 36 years, male & $\boldsymbol{V}$ & $\checkmark$ & 0.15 & 0.27 & $\checkmark$ \\
\hline 36 years, male & & $\checkmark$ & 1.09 & 0.12 & $\checkmark$ \\
\hline 37 years, male & $\checkmark$ & $\checkmark$ & 0.02 & 0.04 & $\boldsymbol{V}$ \\
\hline 37 years, male & $\boldsymbol{V}$ & $\checkmark$ & 0.11 & 0.02 & $\checkmark$ \\
\hline 37 years, male & & $\checkmark$ & 0.19 & 0.23 & $\checkmark$ \\
\hline 39 years, male & & $\checkmark$ & 0.05 & 0.03 & $\checkmark$ \\
\hline 39 years, male & $\checkmark$ & $\checkmark$ & 0.22 & 0.47 & $\checkmark$ \\
\hline 39 years, male & $\checkmark$ & $\checkmark$ & 0.56 & 0.72 & $\checkmark$ \\
\hline 41 years, male & & $\checkmark$ & 0.09 & 0.01 & $\checkmark$ \\
\hline 41 years, male & & $\checkmark$ & 0.11 & 0.05 & $\checkmark$ \\
\hline 41 years, male & & $\checkmark$ & 18.05 & 40.9 & $\checkmark$ \\
\hline 42 years, male & & $\checkmark$ & 0.14 & 0.02 & $\checkmark$ \\
\hline 42 years, male & & $\checkmark$ & 0.45 & 0.21 & $\checkmark$ \\
\hline 43 years, male & $\checkmark$ & $\checkmark$ & 0.17 & 0 & $\checkmark$ \\
\hline 44 years, male & & $\checkmark$ & 0.11 & 0.98 & $\checkmark$ \\
\hline 44 years, male & & $\checkmark$ & 0.18 & 0.04 & $\checkmark$ \\
\hline 46 years, male & & $\checkmark$ & 0.04 & 0.02 & Negative \\
\hline 46 years, male & $\checkmark$ & $\checkmark$ & 4.72 & 0.05 & $\checkmark$ \\
\hline 48 years, male & & $\checkmark$ & 0.61 & 0 & $\checkmark$ \\
\hline 51 years, male & $\checkmark$ & $\checkmark$ & 0.05 & 0.01 & $\checkmark$ \\
\hline 55 years, male & $\checkmark$ & $\checkmark$ & 0.06 & 0.03 & $\checkmark$ \\
\hline 57 years, male & $\checkmark$ & $\checkmark$ & 0.02 & 0 & $\checkmark$ \\
\hline 58 years, male & $\checkmark$ & $\checkmark$ & 0.61 & 0.04 & $\checkmark$ \\
\hline
\end{tabular}

the costs of the immunoblotting procedures involved in such tests are too high for routine use at present. For routine screening, the commercial test kits are more practicable and cost-effective.

In our study, up to $27.8 \%$ of all claw trimmers with negative results using commercial test kits showed positive results with the self-prepared allergen mix extracted from cattle hair. Similar results have been previously reported (Heutelbeck et al. 2007; Prahl et al. 1978; Ylönen et al. 1990): some farmers with a negative result using commercially available serological allergy tests showed distinct reactions with cattle allergens in immunoblotting experiments (Heutelbeck et al. 2009). Such inconsistencies between clinical symptoms and in vivo or in vitro diagnostics may result from the absence of certain important allergens in the commercial extract used for testing. The strong association of work-related allergy symptoms with cattle-related sensitization in this study may be a result of the unique characteristics of claw trimming with constantly high cattle allergen exposure. However, regarding the sensitization pattern in the immunoblot experiments, we found more specific reactivity at molecular weights of about $16 \mathrm{kDa}$ rather than in the range of about $20 \mathrm{kDa}$ previously described as the major allergen Bos d 2 (Prahl et al. 1982; Ylönen et al. 1992; Rautiainen et al. 1997). The relevance of these proteins to an earlier stage of sensitization should be addressed in further studies.

To improve the sensitivity of commercial test kits, this study proposes an optimized cutoff level for two commercially available cattle allergen extracts. Cutoff levels around $0.35 \mathrm{kU} / \mathrm{l}$ are currently in use, indicating that this is the level at which the sample loses its ability to distinguish differences in the IgE concentration. However, even at a cutoff level of $0.05 \mathrm{kU} / \mathrm{l}$, we found distinctly positive reactions in immunoblotting in a few cases. In summary, we propose an optimized cutoff level of $0.2 \mathrm{kU} / 1$ for both commercial test kits to optimize the diagnostic efficiency without losing specificity.

The prevalence of atopic sensitization against ubiquitous allergens in farmers has been assessed before in only a 

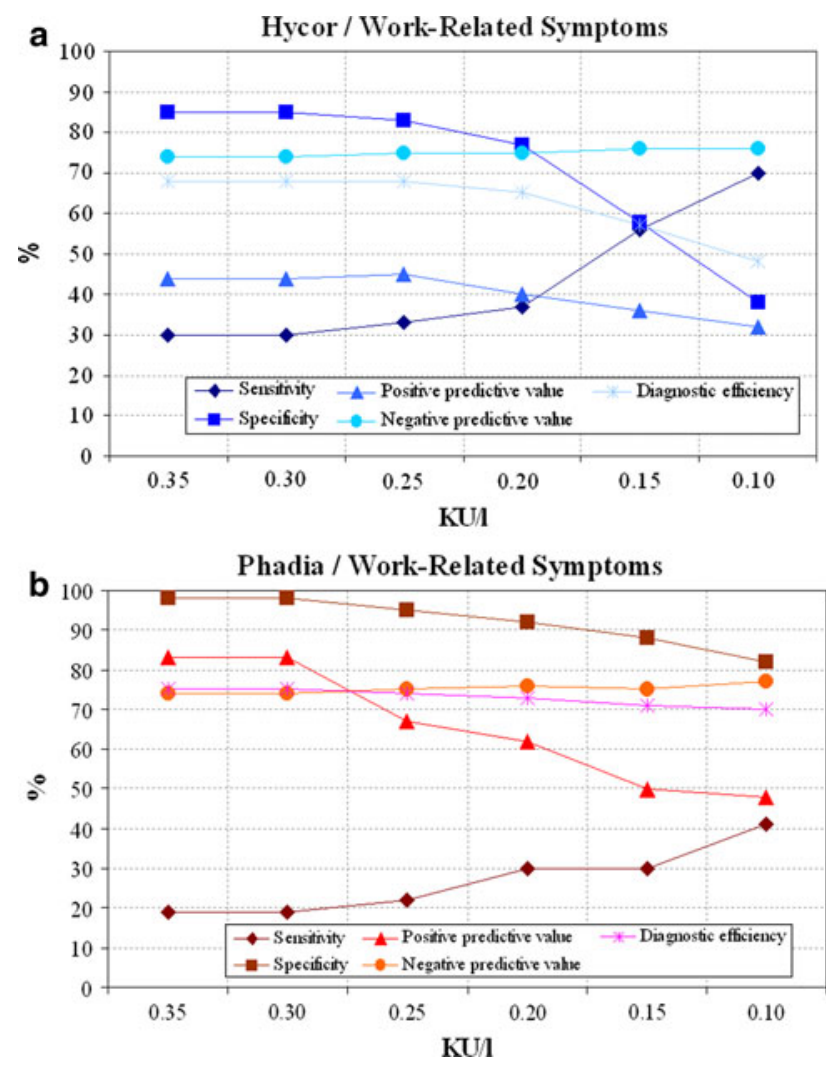

Fig. 3 Sensitivity, specificity and diagnostic efficacy of the commercial cattle allergen tests (a Hycor, b Phadia) to identify the symptomatic claw trimmers, given in 27 claw trimmers with and 65 without work-related symptoms. We used different cut points between 0.35 and $0.10 \mathrm{kU} / \mathrm{l}$ (WS work-related symptoms)

small number of studies: high atopy rates up to 35 and $49 \%$, respectively, have been previously described in Polish and Austrian farming students (Prior et al. 1996; Spiewak et al. 2001). During the last few years, several studies have pointed to protection from childhood allergy in children who lived on farms (overview in: von Mutius 2007). However, in contrast, the results of our study with a rather high sensitization rate of 38\% against ubiquitous allergens approve the findings of an atopic sensitization in association with an agricultural occupation in adulthood. Whether intensity and continuity of farming exposure or other factors might be decisive for these discrepant findings in adults and children on farms remain to be clarified.

Epidemiological studies on cattle allergy in dairy farming are rare and difficult to compare because of methodological differences. However, their results underline the elevated risk of animal farmers for occupationrelated respiratory allergy (Danuser et al. 2001; Heutelbeck et al. 2007; Omland 2002; Piipari and Keskinen 2005; Terho 1985). In dairy-related workplaces, one of the occupations with the closest contact to cattle in everyday work is claw trimming. It is unclear why cattle-related sensitization in a high percentage of claw trimmers with work-related symptoms remains undetected. Possibly, economic aspects outweigh the need to initiate medical intervention at an earlier stage. Additionally, some workers may not interpret initial symptoms as an early sign of a chronic allergic disease.

Our results underline the need for prevention strategies, in particular measures to identify populations at risk of allergy. One suitable measure in this context could be screening for sensitizations against ubiquitous allergens, which were found in the samples of nearly all cattle-sensitized claw trimmers. Since more than $90 \%$ of cattle-allergic farmers, regardless of their age, showed a sensitization to least one ubiquitous allergen, atopic predisposition seems to be a relevant and suitable screening factor (Heutelbeck et al. 2007). After identifying at-risk populations based on such criteria, individuals should be screened in a second step for work-related sensitizations with effective diagnostic methods. In selected groups, e.g., when screening for sensitizations at an early stage, we propose to choose a lower cutoff level of $0.2 \mathrm{kU} / \mathrm{l}$ when using commercially available allergen extracts. If commercial test kits still show negative results in contradiction to observed symptoms, individually prepared extracts made of hair of the farmers' own cattle should be used in another step for additional testing. Identification and exclusion of susceptible workers seem to be inefficient, particularly when the marker of susceptibility (e.g., atopy) is prevalent in the general population. Such surveillance programs aimed at early identification may help to initiate suitable protective strategies such as use of a breathing mask or similar technical equipment (e.g., allergen-proof working clothes) for all tasks. The type of breathing mask should be selected according to the individual working environment. This could help minimize the contact of the airways and the skin with the allergens, especially in individuals with known atopic predisposition.

In summary, our experiments are the first to present test results of a self-prepared cattle allergen mix that was designed to represent the full spectrum of cattle allergens present in a typical agricultural workplace. Additional tests with self-made cattle hair extracts can help to bridge the diagnostic gap seen in patients showing cattle-related symptoms, but negative results in tests using commercially available extracts. A suitable prevention strategy to identify the population at risk of cattle allergy could include screening for sensitizations against ubiquitous allergens, which we found in the samples of almost all cattle-sensitized claw trimmers. In selected groups, e.g., when screening for sensitizations at an early stage, we propose to choose a lower cutoff level of $0.2 \mathrm{kU} / \mathrm{l}$ with commercially available allergen extracts. 
Acknowledgments We are grateful for all the support that we received in the course of our study. We would like to thank in particular Dietrich Landmann (Echem, Germany) and the claw trimmer unions, Anke Seeckts, Petra Tucholla and Bianca Rohland (Göttingen, Germany) for technical support in immunoblotting.

Conflict of interest The authors declare that they have no conflict of interest.

Open Access This article is distributed under the terms of the Creative Commons Attribution Noncommercial License which permits any noncommercial use, distribution, and reproduction in any medium, provided the original author(s) and source are credited.

\section{References}

Danuser B, Weber C, Künzli N, Schindler C, Nowak D (2001) Respiratory symptoms in Swiss farmers: an epidemiological study of risk factors. Am J Ind Med 39(4):410-418

Fuchs E, Gronemeyer W, Bandilla K (1981) Reibtest und Tierhaarallergie, zugleich ein klinischer Beitrag zum Problem der „Rassespezifität“. Allergologie 4:241-248

Greskevitch M, Kullman G, Bang KM, Mazurek JM (2007) Respiratory disease in agricultural workers: mortality and morbidity statistics. J Agromed 12(3):5-10

Heutelbeck AR, Janicke N, Hilgers R, Kütting B, Drexler H, Hallier E, Bickeböller H (2007) German cattle allergy study (CAS): public health relevance of cattle-allergic farmers. Int Arch Occup Environ Health 81:201-208

Heutelbeck AR, Junghans C, Esselmann H, Hallier E, Schulz TG (2009) Exposure to allergens of different cattle breeds and their relevance in occupational allergy. Int Arch Occup Environ Health 82:1123-1131

Linaker C, Smedley J (2002) Respiratory illness in agricultural workers. Occup Med (Lond) 52(8):451-459

Omland $\varnothing$ (2002) Exposure and respiratory health in farming in temperate zones-a review of the literature. Ann Agric Environ Med 9(2):119-136
Piipari R, Keskinen H (2005) Agents causing occupational asthma in Finland in 1986-2002: cow epithelium bypassed by moulds from moisture-damaged buildings. Clin Exp Allergy 35(12):16321637

Prahl P, Weeke B, Löwenstein H (1978) Quantitative immunoelectrophoresis analysis of extract from cow hair and dander. Allergy 33:241-253

Prahl P, Bucher D, Plesner T, Weeke B, Löwenstein H (1982) Isolation and partial characterisation of three major allergens in an extract from cow hair and dander. Int Arch Allergy Appl Immunol 67:293-301

Prior C, Falk M, Frank A (1996) Early sensitization to farmingrelated antigens among young farmers: analysis of risk factors. Int Arch Allergy Immunol 111:182-187

Rautiainen J, Rytkönen M, Virtanen T, Pentikäinen J, Zeiler T, Mäntyjärvi R (1997) BDA20, a major bovine dander allergen characterized at the sequence level, is Bos d 2. J Allergy Clin Immunol 100:251-252

Reijula K, Patterson R (1994) Occupational allergies in Finland in 1981-91. Allergy Proc 15(3):163-168

Spiewak R, Gora A, Horoch A, Dutkiewicz J (2001) Atopy, allergic disease and work-related symptoms among students of agricultural schools: first results of the Lublin study. Ann Agric Environ Med 8:261-267

Terho EO, Husman K, Vohlonen I, Rautalahti IM, Tukiainen H (1985) Allergy to storage mites or cow dander as a cause of rhinitis among Finnish dairy farmers. Allergy 40(1):23-26

von Mutius E (2007) Asthma and allergies in rural areas of Europe. Proc Am Thorac Soc. 4(3):212-216

Wortmann F (1984) Sensibilisierungen gegenüber Haaren und Epithelien verschiedener Tierindividuen (bei fraglicher Rasseidentität)- Bedeutung der Testung mit Material des patienteneigenen Allergenspenders. Allergologie 7:69-73

Ylönen J, Nuutinen J, Rautiainen M, Ruoppi P, Mäntyjärvi R, Virtanen T (1990) Comparative analysis of bovine extracts by immunoblotting and ELISA inhibition. Allergy 45:30-39

Ylönen J, Mäntyjärvi R, Taivainen A, Virtanen T (1992) IgG and IgE antibody responses to cow dander and urine in farmers with cowinduced asthma. Clin Exp Allergy 22:83-90 